\title{
Irbesartan ameliorates myocardial fibrosis in diabetic cardiomyopathy rats by inhibiting the TGFß1/Smad2/3 pathway
}

\author{
MIN ZONG, HUA ZHAO, QIANG LI, YANBING LI and JIANJUN ZHANG \\ Department of Cardiology, Beijing Chaoyang Hospital, Capital Medical University, Beijing 100043, P.R. China
}

Received July 27, 2019; Accepted May 15, 2020

DOI: $10.3892 /$ etm.2020.9245

\begin{abstract}
Myocardial fibrosis (MF) is an important pathological change in diabetic cardiomyopathy. The aim of the present study was to investigate whether irbesartan serves a role in improving MF in a diabetic rat model. Fasting blood glucose (FBG), total cholesterol (TC), triglyceride (TG), high-density lipoprotein cholesterol (HDL-C) and low-density lipoprotein cholesterol (LDL-C) levels were measured in rats using biochemical methods. Heart weight index (HWI), left ventricular weight index (LVWI), left ventricular systolic pressure (LVSP) and left ventricular end-diastolic pressure (LVEDP) were also measured, whilst type I collagen and hydroxyproline content in myocardial tissue was quantified. Western blotting was used to measure the expression of transforming growth factor $\beta 1$ (TGF $\beta 1$ ), phosphorylated (p)-Smad $2 / 3$ and collagen type I $\alpha 1$ chain (COL1A1) inmyocardial tissues or rat cardiac fibroblast (RCF) cells. Cell proliferation was measured using EdU staining. Procollagen type III N-terminal peptide (PIIINP) content, FBG, TC, TG and LDL-C levels were found to be significantly higher, whilst HDL-C levels were found to be significantly lower in rats in the diabetic group. Those in the diabetic group also exhibited significantly elevated HWI, LVWI, LVEDP, myocardial tissue type I collagen content and hydroxyproline content values, but significantly reduced LVSP. Changes in the aforementioned indicators were reversed after treatment with irbesartan, where the protein expression levels of TGF $\beta 1$ and p-Smad2/3 in myocardial tissue were also significantly reduced. In RCF cells, irbesartan significantly reversed high glucose-induced upregulation of TGF $\beta 1$ expression, Smad2/3 phosphorylation and COL1A1 expression, as well as reducing cell proliferation and rat type I PICP and PIIINP levels. Application of pirfenidone produced additive effects on reducing the expression levels of the proteins aforementioned when combined with irbesartan. Therefore,
\end{abstract}

Correspondence to: Dr Jianjun Zhang, Department of Cardiology, Beijing Chaoyang Hospital, Capital Medical University, 5 Jing-Yuan Road, Shijingshan, Beijing 100043, P.R. China

E-mail: jianjunzhang890@126.com

Key words: irbesartan, diabetes mellitus, myocardial fibrosis, transforming growth factor $\beta 1, \operatorname{Smad} 2 / 3$ the present results demonstrated that irbesartan reduced the activity of the TGF $\beta 1 / \mathrm{Smad} 2 / 3$ pathway and ameliorated diabetic MF by downregulating the expression of TGF $\beta 1$.

\section{Introduction}

Diabetic mellitus (DM), which describes a series of metabolic disorders affecting protein, fat and electrolytes, is caused by the absolute or relative deficiency of insulin secretion or decreased insulin sensitivity in target tissue cells, which is mainly characterized by abnormally elevated blood sugar content $(1,2)$. The metabolic disorder caused by DM directly affects cardiac myocytes and cardiac fibroblasts, changing the function of cardiac myocytes and the deposition of collagen in the cardiac interstitium, leading to decreases in myocardial compliance and diastolic function (3). As the disease progresses, the systolic function of the heart also decreases, causing congestive heart failure, cardiogenic shock and sudden mortality, which seriously affect the life and health of patients with DM (4). Myocardial fibrosis (MF) is an important factor in cardiac diastolic, contractile function impairment and congestive heart failure during the progression of diabetic cardiomyopathy (DCM) (5-7).

Previous studies have shown that transforming growth factor $\beta 1$ (TGF $\beta 1$ ) regulates the transcription of related extracellular matrix (ECM) components by activating downstream Smad proteins and serves an important regulatory role in fibrosis in various tissues and organs (8-10). In the condition of diabetic pathological hyperglycaemia, the renin angiotensin aldosterone system (RAAS) is activated, which increases blood circulation and angiotensin II (Ang II) content in the myocardium (11). Furthermore, Ang II increases the expression of a variety of fibrotic factors, including transforming growth factor $\beta$ (TGF- $\beta$ ), connective tissue growth factor (CTGF) and collagen in the myocardial interstitium whilst reducing the degradation of collagen, thus promoting the development of diabetic MF $(12,13)$. Irbesartan is an Ang II receptor antagonist that can effectively block the binding of Ang II to its receptor and inhibit its downstream biological functions (14). Currently, irbesartan is widely used in the clinic, mainly for the treatment of hypertension and type II diabetic nephropathy with hypertension (15). In addition, previous studies have reported that irbesartan can improve MF induced by hypertension (16-18); however, to the best of our knowledge, there have been an insufficient number of studies on the effects of irbesartan on 
MF in patients with DM. Therefore, the aim of the present study was to investigate whether irbesartan serves a role in improving MF in a diabetic rat model.

\section{Materials and methods}

Ethical statement. The present study was approved by the Animal Ethics Committee and was conducted in accordance to the relevant agreements with the Beijing Chaoyang Hospital of the Capital Medical University (approval no. 201705231). All procedures were performed in accordance with the Guidance Suggestions for the Care and Use of Laboratory Animals (19).

Main reagents and materials. DMEM, FBS and penicillinstreptomycin were purchased from Gibco (Thermo Fisher Scientific,Inc.), and ahydroxyproline assay kit(cat.no.A030-1-1) was purchased from Nanjing Jiancheng Bioengineering Institute. Irbesartan was purchased from Sanofi (Hangzhou) Pharmaceutical Co., Ltd. Healthy adult male Sprague Dawley (SD) rats ( $\mathrm{n}=30$; age, 6 weeks; weight, 220-240 g) were acquired from the Guangdong Medical Laboratory Animal Center. A high-fat and high-sugar diet was purchased from Jiangsu Synergy Pharmaceutical Bioengineering Co., Ltd. (https://www.jsxtsw.com/) and streptozotocin (STZ) citrate buffer was purchased from Sigma-Aldrich (Merck KGaA). A rat collagen I ELISA kit (cat. no. 20180302A) was purchased from Suzhou Calvin Biotechnology Ltd. (https://biocalvin. biogo.net/) and rat cardiac fibroblasts (RCFs) were purchased from Cloud-Clone Corp. (cat. no. CSI095Ra01). The TGF 31 inhibitor pirfenidone was purchased from Selleck Chemicals. Rabbit anti-human TGF $\beta 1$ (cat. no. ab92486; 1:2,000), anti-phosphorylated (p)-Smad2/3 (cat. no. ab272332; 1:2,000), Smad2/3 (cat. no. ab63672, 1:2,000), and anti-collagen type I $\alpha 1$ (COLIA1; cat. no. ab34710; 1:2,000) polyclonal antibodies were purchased from Abcam. ECL chemiluminescence solutionand bicinchoninic acid protein quantitative detection kits were purchased from Beyotime Institute of Biotechnology. Rat type I procollagen carboxyl-terminal peptide (PICP; cat. no.CSB-E08081r) and Type III procollagen amino terminal pro-peptide (PIIINP) ELISA kits (cat. no. CSB-E08096r) were purchased from CusabioTechnology LLC. Chloral hydrate and PBS were obtained from Sangon Biotech Co., Ltd. Biological function was assessed with a BL-420L biological signal collection system (Chengdu Taimeng Software Co., Ltd.), and flow cytometry was performed using a Beckman Coulter FC500 MCL flow cytometer (Beckman Coulter, Inc.).

Establishment of the DCM rat model. Rats were allowed free access to water and food under $22 \pm 2^{\circ} \mathrm{C}, 55 \pm 10 \%$ humidity and 12-h light/dark cycle.A rat model of type 2 DM was established by feeding freely with a high-fat and high-sugar diet combined with an intraperitoneal injection of a low dose of STZ ( $40 \mathrm{mg} / \mathrm{kg}$ ). After 1 week of adaptive feeding of SD rats, the model was established. DM model rats were fed a high-fat and high-sugar diet for 2 months. After the rats were fasted for $12 \mathrm{~h}, 1 \% \mathrm{STZ}$ citrate buffer was injected into the abdominal cavity $(40 \mathrm{mg} / \mathrm{kg}$ ). The model was considered successful when the fasting blood glucose (FBG) concentration was $>16.7 \mathrm{mmol} / \mathrm{l}$ for 3 consecutive days. Blood was obtained by using the blood glucose meter blood sampling needle to pierce the tip of the tail of the rat and then squeezed a drop of blood onto the blood glucose test paper to test the blood glucose level. Food intake, drinking water intake and urine output were significantly higher in model rats compared with control rats, indicating that the DM model was successfully established. The rats remained on the high-fat and high-sugar diet for a further 10 weeks.

The eight rats in the control group were fed on a standard diet, given intraperitoneal injections of citrate buffer $(10 \mathrm{ml} / \mathrm{kg}$, no STZ) after 2 months of feeding and continued on the standard feed until the end of the experiment.

Irbesartan treatment of DCM rats. In total, 30 rats were randomly divided into the blank control group $(n=8)$ and the DCM1 group $(n=22)$. The remaining rats in which the DCM model was successfully established were divided into two groups: DCM group $(n=6)$ and the DCM + irbesartan group $(\mathrm{n}=6)$. Irbesartan was intragastrically administered at $50 \mathrm{mg} / \mathrm{kg}$ (20) once daily for 10 weeks. In the DCM and blank control groups, a corresponding volume of saline $(10 \mathrm{ml} / \mathrm{kg})$ was administered by gavage. DCM rats were fed the high-fat and high-sugar diet, whilst rats in the blank control group were fed on the standard maintenance diet for 10 weeks.

Blood glucose and blood lipid detection. Rats were anaesthetized with an intraperitoneal injection of chloral hydrate (300 $\mathrm{mg} / \mathrm{kg}$ ), before $2 \mathrm{ml}$ blood was obtained from the orbital venous plexus and a sterile cotton ball was used to stop the bleeding immediately after pressing the orbit, following which the rats resumed normal diet and activities. FBG, total cholesterol (TC), triglyceride (TG), high-density lipoprotein cholesterol (HDL-C) and low-density lipoprotein cholesterol (LDL-C) levels were measured with a 7180 Automatic Biochemical Analyzer (Hitachi, Ltd.).

Heart weight index (HWI) and left ventricular weight index ( $L V W I)$ determination. After the rats were weighed, they were anaesthetized with an intraperitoneal injection of chloral hydrate $(300 \mathrm{mg} / \mathrm{kg})$ and the hearts were removed. After the heart tissue was washed with saline and filter paper was used to absorb excess water, each heart was weighed. Subsequently, the left and right atrium and the right ventricle were removed, and the left ventricle was weighed to provide the LVW. HWI and LVWI were calculated using the following equations: $\mathrm{HWI}=\mathrm{HW} /$ body weight $(\mathrm{BW} ; \mathrm{mg} / \mathrm{g}$ ) and LVWI=LVW/BW $(\mathrm{mg} / \mathrm{g})$. The heart tissue was then stored at $-80^{\circ} \mathrm{C}$ for further experimentation.

Cardiac function evaluation. Cardiac haemodynamic indexes of each group were measured by cannulation of the carotid artery, and cardiac function was evaluated after intraperitoneal injection of $10 \%$ chloral hydrate $(300 \mathrm{mg} / \mathrm{kg})$. The right cervical artery was isolated, exposed and cannulated. The left ventricle was cannulated through the right common carotid artery. The left ventricular systolic pressure (LVSP) and left ventricular end-diastolic pressure (LVEDP) were detected using the BL-420L biological signal collection system.

Detection of myocardial hydroxyproline. In total, $100 \mathrm{mg}$ myocardial tissue and $400 \mu \mathrm{l}$ pre-cooled PBS were added to 
a manual glass homogenizer, which was then evenly grinded it in an ice box and poured into a $1.5 \mathrm{ml}$ tube. This mixture was centrifuged at $4,000 \times \mathrm{g} 5 \mathrm{~min}$ at $4^{\circ} \mathrm{C}$, before the supernatant was collected. The hydroxyproline content was detected by ELISA according to manufacturer's protocol. The plates included blank, standard and sample wells. A myocardial hydroxyproline standard sample $(10 \mu \mathrm{l})$ was first diluted in a $40 \mu \mathrm{l}$ solution. The plate was sealed and incubated at $37^{\circ} \mathrm{C}$ for $30 \mathrm{~min}$. The sealing film was then carefully removed, the liquid was discarded and the plate was dried and washed with PBS five times for $30 \mathrm{sec}$ each. Enzyme-labelling reagent (50 $\mu \mathrm{l})$ was added to each well (except the blank well), and the plate was sealed and incubated at $37^{\circ} \mathrm{C}$ for $30 \mathrm{~min}$. The sealing membrane was carefully removed from the plate, and the wells were filled with washing liquid. This process was repeated five times. Chromogenic agent A (50 $\mu \mathrm{l})$ was added to each well and then $50 \mu \mathrm{l}$ colour agent $\mathrm{B}$ was added. Subsequently, the plates were lightly shaken at $37^{\circ} \mathrm{C}$ for $15 \mathrm{~min}$ in the dark. Terminating solution $(50 \mu \mathrm{l})$ was added to each well to terminate the reaction. With the blank well set to zero, the absorbance of each well was measured at $450 \mathrm{~nm}$.

RCF cell culture and treatment. RCF cells were inoculated into culture dishes (1x10\% $/$ well), and DMEM supplemented with $10 \%$ FBS and $1 \%$ penicillin-streptomycin was added. Cells were cultured in a $\mathrm{CO}_{2}$ culture box with $5 \% \mathrm{CO}_{2}$ at $37^{\circ} \mathrm{C}$. After the cells were grown to $80-90 \%$ confluence, cells were then cultured at a 1:5 ratio and tested within four generations.

According to the different treatment concentrations of D-glucose (Dalian Meilun Biotechnology Co., Ltd.), the RCF cells were divided into the normal-glucose concentration group (5 mM D-glucose; control group) and the high-glucose (HG) treatment group (25 mM D-glucose). RCF cells treated with HG were further divided into three groups: HG group, the $\mathrm{HG}+$ irbesartan $(10 \mu \mathrm{M})$ group and the $\mathrm{HG}+$ irbesartan $(10 \mu \mathrm{M})+$ pirfenidone $(5 \mathrm{mM})$ group. Cells in each treatment group were cultured $\left(5 \% \mathrm{CO}_{2}, 37^{\circ} \mathrm{C}\right)$ for $48 \mathrm{~h}$ in vitro and collected for mRNA and protein detection.

EdU detection of cell proliferation. After RCF cells were incubated in complete culture medium for $2 \mathrm{~h}$ at $37^{\circ} \mathrm{C}$ with $10 \mu \mathrm{l} \mathrm{EdU,} \mathrm{the} \mathrm{cells} \mathrm{were} \mathrm{cultured} \mathrm{for} \mathrm{an} \mathrm{additional} 48 \mathrm{~h}$ in accordance with the aforementioned groups and digested with $0.2 \%$ trypsin at $25^{\circ} \mathrm{C}$ for $60 \mathrm{sec}$. After PBS washing and centrifugation $\left(500 \mathrm{x} \mathrm{g}, 25^{\circ} \mathrm{C}, 5 \mathrm{~min}\right)$, cells were incubated in $10 \%$ neutral formaldehyde at room temperature for $15 \mathrm{~min}$. PBS was then added to the cells, which were then centrifuged at $300 \mathrm{x} \mathrm{g}$ for $5 \mathrm{~min}$ at $25^{\circ} \mathrm{C}$. Subsequently, $100 \mu 10.5 \%$ Triton $\mathrm{X}-100$ in PBS was added to the cells at room temperature and $500 \mu 1$ reaction liquid was added for detection. Cell proliferation was detected after incubation at room temperature for $30 \mathrm{~min}$, followed by the addition of $3 \mathrm{ml}$ washing liquid and centrifugation of the washing liquid. The cell pellets were then resuspended in $500 \mu \mathrm{l}$ washing liquid and flow cytometry was performed using a Beckman Coulter FC 500 MCL flow cytometer, which was analyzed using the FlowJo software (FlowJo v7.6.5; FlowJo LLC).

ELISA detection of type I collagen in rat tissues and PICP and PIIINP in RCF cell culture medium. PBS was added to the myocardial tissue at 1:5 (myocardial tissue:PBS), which was then homogenized and centrifuged at 1,000 x g $10 \mathrm{~min}$ at $4^{\circ} \mathrm{C}$ before the supernatant was obtained. Type I collagen content was then measured in the supernatant according to the manufacturer's instructions.

RCF cells from each treatment group were cultured for $48 \mathrm{~h}$. The supernatant of the culture medium was collected and the levels of PICP and PIIINP in the culture medium were detected by ELISA, according to the manufacturer's instructions.

Western blotting of protein expression. After SDS lysis buffer (cat. no. P0013G; Beyotime Institute of Biotechnology) was added to the cells or myocardial homogenate, each sample was boiled for $5 \mathrm{~min}$ and the bicinchoninic acid method was used to detect the protein concentration. In total, $60 \mu \mathrm{g}$ sample was then separated by $5 \%$ SDS-PAGE and transferred to a PVDF membrane. The membrane was blocked with 5\% skimmed milk powder for $1 \mathrm{~h}$ at room temperature and then incubated with primary antibodies TGF $\beta 1(1: 2,000)$, p-Smad2/3 (1:2,000), Smad2/3 (1:2,000), COLIA1 (1:2,000), $\beta$-actin (1:500; cat. no. ab179467; Abcam) overnight at $4^{\circ} \mathrm{C}$. After the membrane was washed with PBS $+10 \%$ Tween-20 for three times, the membranes were incubated with an appropriate horseradish peroxidase-labelled goat anti-rabbit IgG secondary antibody (1:2,500; cat. no. G-21234; Thermo Fisher Scientific, Inc.) for $1 \mathrm{~h}$ at room temperature. The membranes were subsequently detected with ECLand analyzed using the Quantity One image analysis software (version 4.5.0; Bio-Rad Laboratories, Inc.).

Statistical analysis. Statistical analysis was performed using SPSS 18.0 software (SPSS, Inc.). Data are presented as the mean \pm standard deviation from three experimental repeats. A t-test was used to compare data between two groups. Differences among $>2$ experimental groups were evaluated by one-way ANOVA followed by Tukey's test. $\mathrm{P}<0.05$ considered to indicate a statistically significant difference.

\section{Results}

Abnormal blood glucose and blood lipid content in DCM model rats. The blood glucose test results indicated that the FBG content in the DCM group was significantly higher compared with the control group $(\mathrm{P}<0.001)$. Moreover, the levels of TC, TG and LDL-C in the DCM group were significantly higher compared with the control group $(\mathrm{P}<0.05)$, while the levels of HDL-C were significantly lower $(\mathrm{P}<0.05)$, as presented in Table I.

DCM model rats exhibit notable $M F$. The cardiac test results demonstrated that HWI and LVWI in the DCM group were significantly higher compared with the control group $(\mathrm{P}<0.001$; Table II). ELISA results suggested that the myocardial concentrations of type I collagen and hydroxyproline in the DCM group were significantly increased compared with that in the control group $(\mathrm{P}<0.001$; Table II). The LVSP were significantly decreased $(\mathrm{P}<0.05$; Table II) and LVEDP were significantly increased $(\mathrm{P}<0.001$; Table II) in the DCM group compared with those in the control group $(\mathrm{P}<0.001$; Table II). 
Table I. Blood glucose and blood lipid levels in two groups of rats.

\begin{tabular}{|c|c|c|c|c|c|}
\hline Index & FBG (mmol/l) & $\mathrm{TC}(\mathrm{mmol} / \mathrm{l})$ & TG (mmol/l) & HDL-C (mmol/l) & $\mathrm{LDL}-\mathrm{C}(\mathrm{mmol} / \mathrm{l})$ \\
\hline Control group $(n=8)$ & $4.69 \pm 0.58$ & $1.23 \pm 0.19$ & $1.33 \pm 0.21$ & $1.03 \pm 0.11$ & $0.88 \pm 0.09$ \\
\hline DCM1 group $(n=6)$ & $23.61 \pm 3.89$ & $2.71 \pm 0.39$ & $2.59 \pm 0.42$ & $0.84 \pm 0.08$ & $1.06 \pm 0.15$ \\
\hline$t$ & 11.816 & 9.431 & 7.407 & 3.568 & 2.807 \\
\hline P-value & $<0.001$ & $<0.001$ & $<0.001$ & 0.002 & 0.008 \\
\hline
\end{tabular}

DCM1 group, diabetic cardiomyopathy 1 group; FBG, fasting blood glucose; TC, total cholesterol; TG, triglyceride; HDL-C, high density lipoprotein cholesterol; LDL-C, low density lipoprotein cholesterol.

Table II. Comparison of HWI, LVWI and myocardial fibrosis indexes in two groups of rats.

\begin{tabular}{|c|c|c|c|c|c|c|}
\hline Index & $\begin{array}{c}\text { HWI } \\
(\mathrm{mg} / \mathrm{g})\end{array}$ & $\begin{array}{l}\text { LVWI } \\
(\mathrm{mg} / \mathrm{g})\end{array}$ & $\begin{array}{l}\text { Collagen I } \\
(\mathrm{ng} / \mathrm{g})\end{array}$ & $\begin{array}{l}\text { Hydroxyproline } \\
\qquad(\mu \mathrm{g} / \mathrm{mg})\end{array}$ & $\begin{array}{c}\text { LVSP } \\
(\mathrm{mmHg})\end{array}$ & $\begin{array}{l}\text { LVEDP } \\
(\mathrm{mmHg})\end{array}$ \\
\hline Control group $(n=8)$ & $2.81 \pm 0.33$ & $2.09 \pm 0.22$ & $115.63 \pm 13.77$ & $33.66 \pm 6.29$ & $127.9 \pm 13.8$ & $3.1 \pm 0.4$ \\
\hline DCM1 group $(n=6)$ & $4.05 \pm 0.38$ & $3.14 \pm 0.28$ & $238.51 \pm 34.65$ & $76.58 \pm 11.34$ & $97.4 \pm 10.9$ & $7.9 \pm 0.9$ \\
\hline$t$ & 6.528 & 7.878 & 8.214 & 9.077 & 4.2 & 11.9 \\
\hline P-value & $<0.001$ & $<0.001$ & $<0.001$ & $<0.001$ & 0.002 & $<0.001$ \\
\hline
\end{tabular}

DCM1 group, diabetic cardiomyopathy 1 group; HWI, heart weight index; LVWI, left ventricular mass index; LVSP, left ventricular systolic pressure; LVEDP, left ventricular end-diastolic pressure.

Table III. Comparison of HWI, LVWI and myocardial fibrosis indexes in two groups of rats.

\begin{tabular}{lccccc}
\hline Index & FBG $(\mathrm{mmol} / \mathrm{l})$ & HWI $(\mathrm{mg} / \mathrm{g})$ & LVWI $(\mathrm{mg} / \mathrm{g})$ & Collagen I (ng/g) & Hydroxyproline $(\mu \mathrm{g} / \mathrm{mg})$ \\
\hline DCM group (n=6) & $22.85 \pm 3.77$ & $4.04 \pm 0.36$ & $3.16 \pm 0.26$ & $229.67 \pm 31.92$ & $79.23 \pm 13.31$ \\
DCM + Irbesartan group (n=6) & $21.17 \pm 4.12$ & $3.18 \pm 0.31$ & $2.75 \pm 0.25$ & $158.72 \pm 29.63$ & $52.86 \pm 10.77$ \\
$t$ & 0.737 & 4.434 & 2.784 & 3.990 & 3.773 \\
P-value & 0.478 & 0.001 & 0.019 & 0.003 & 0.004 \\
\hline
\end{tabular}

DCM group, diabetic cardiomyopathy group; FBG, fasting blood glucose; HWI, heart weight index; LVWI, left ventricular mass index.

Table IV. Comparison of LVSP and LVEDP test results in two groups of rats.

\begin{tabular}{lcr}
\hline Index & $\begin{array}{c}\text { LVSP } \\
(\mathrm{mmHg})\end{array}$ & $\begin{array}{r}\text { LVEDP } \\
(\mathrm{mmHg})\end{array}$ \\
\hline DCM group (n=6) & $96.7 \pm 11.3$ & $9.4 \pm 1.3$ \\
DCM + Irbesartan group (n=6) & $116.9 \pm 12.8$ & $5.6 \pm 0.8$ \\
$t$ & 2.898 & 6.098 \\
P-value & 0.016 & $<0.001$ \\
\hline
\end{tabular}

DCM group, diabetic cardiomyopathy group; LVSP, left ventricular systolic pressure; LVEDP, left ventricular end-diastolic pressure.

Irbesartan inhibits the TGF $\beta 1 / S m a d 2 / 3$ pathway and reduces $M F$ in DCM rats. The blood glucose test indicated that there was no significant difference in FBG content between the
DCM group and the irbesartan group. Cardiac measurements identified that, compared with the DCM group, the DCM + irbesartan group had a significantly lower HWI and LVWI $(\mathrm{P}<0.001)$. Furthermore, compared with the DCM group, the DCM + irbesartan group had significantly reduced levels of collagen I and hydroxyproline in myocardial tissue $(\mathrm{P}<0.001)$, as presented in Table III.

Western blotting results demonstrated that the myocardial expression of TGF $\beta 1$ protein in the DCM + irbesartan group was significantly lower compared with the DCM group, and the protein expression of $\mathrm{p}-\mathrm{Smad} 2 / 3$ was also significantly decreased (Fig. 1).

Irbesartan alleviates DM-induced cardiac dysfunction. Compared with the DCM group, the DCM + irbesartan group had a significantly higher LVSP $(\mathrm{P}=0.016)$ but significantly lower LVEDP $(\mathrm{P}<0.001$; Table IV). Thus, these data indicated that irbesartan improved myocardial contractile function and compliance in DM rats. 
A

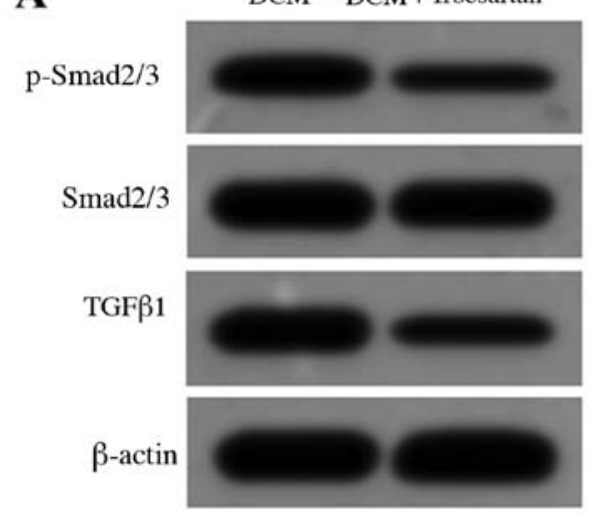

B

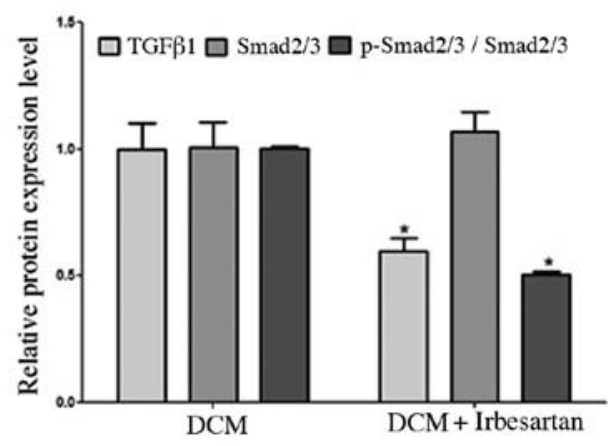

Figure 1. Irbesartan inhibits the activity of the TGF $\beta 1 / \mathrm{Smad} 2 / 3$ pathway in the myocardium in diabetic rats. (A) Western blot analysis of protein expression in the rat myocardium. (B) Statistical comparison of protein expression in the rat myocardium between the two groups. " $\mathrm{P}<0.05$ vs. DCM group. DCM, diabetic cardiomyopathy; TGF $\beta 1$, transforming growth factor $\beta 1$; -, phosphorylated.

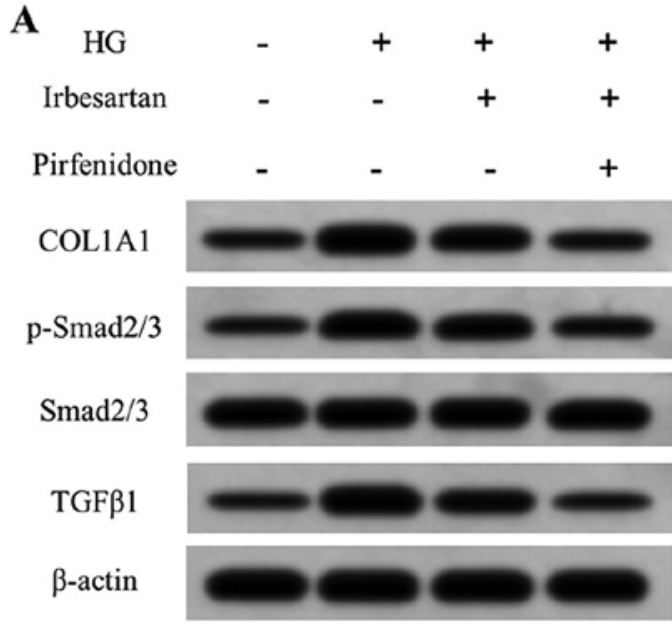

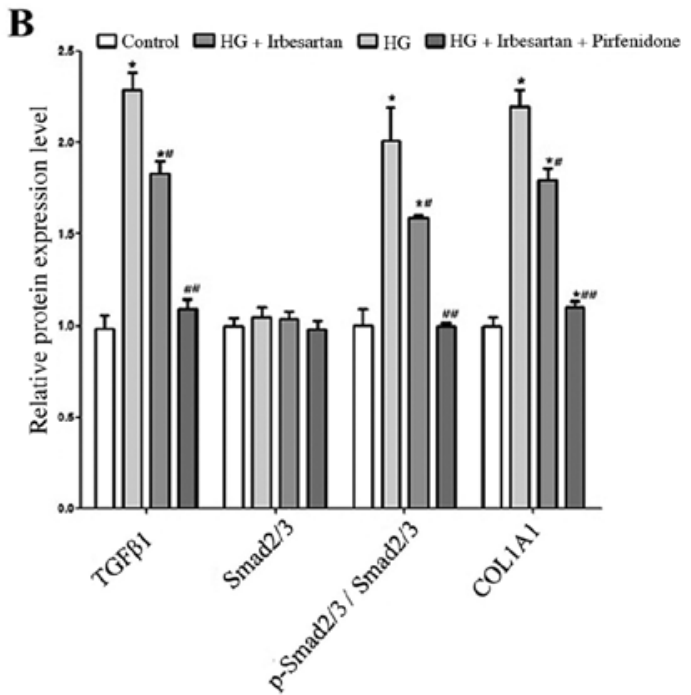

Figure 2. Irbesartan inhibits the TGF $\beta 1 / \mathrm{Smad} 2 / 3$ pathway and HG-induced fibrosis in RCF cells. (A) Western blot analysis of protein expression in RCF cells. (B) Statistical comparison of protein expression in RCF cells. ${ }^{*} \mathrm{P}<0.05$ vs. control group. ${ }^{\#} \mathrm{P}<0.05$, ${ }^{\# \#} \mathrm{P}<0.01$ vs. HG group. HG, high glucose; TGF $\beta 1$, transforming growth factor $\beta 1$; p-, phosphorylated; COL1A1, collagen type I $\alpha 1$ chain.

Irbesartan inhibits the TGF $\beta 1 /$ Smad2/3 pathway and $H G$-induced fibrosis in RCF cells. Western blot analysis results demonstrated that the expression levels of TGF $\beta 1$ and p-Smad2/3 in RCF cells were significantly higher in the HG treatment group compared with the control group. In addition, HG treatment significantly increased the expression of COL1A1 in RCF cells, indicating that the ability of RCF cells to synthesize collagen was enhanced and that fibrosis was significantly changed.

After treatment of HG-exposed RCF cells with irbesartan, TGF $\beta 1$ expression was significantly decreased, TGF $\beta 1 /$ Smad2/3 pathway activity was significantly inhibited, COL1A1 expression was reduced. When combined with irbesartan, treatment with the TGF $\beta 1$ inhibitor pirfenidone reduced TGF $\beta 1 / \mathrm{Smad} 2 / 3$ pathway activity, COL1A1 expression further in RCF cells under HG treatment conditions (Fig. 2).

Irbesartan inhibits $R C F$ cell proliferation and collagen synthesis. The proliferative ability of RCF cells in the HG treatment group was significantly increased compared with the control group. However, irbesartan treatment reduced the RCF proliferative ability, which was further decreased by combined treatment with irbesartan + pirfenidone (Fig. 3).

The ELISA results demonstrated that PICP and PIIINP contents in HG RCF cell culture conditions were significantly higher compared with the control culture conditions. It was found that irbesartan treatment significantly reduced the PICP and PIIINP content in the culture solution, while combined treatment with irbesartan + pirfenidone resulted in the lowest PICP and PIIINP content in the culture solution (Table V).

\section{Discussion}

Previous studies have reported that TGF $\beta 1$ plays an important role in regulating fibrosis in various tissues and organs, such as cardiac (21), liver (22), lung (23) and kidney (24) tissue, by activating downstream Smad proteins. TGF $\beta 1$ must bind with specific cell-surface receptors to exert its corresponding 
A

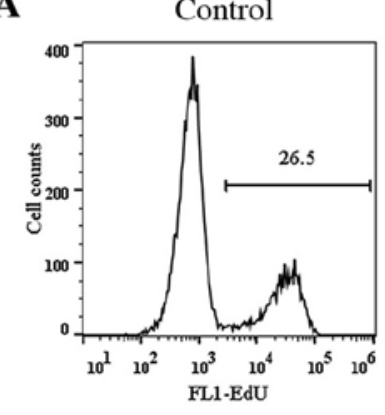

$\mathrm{HG}+$ Irbesartan

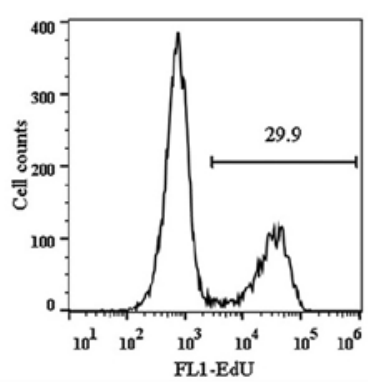

HG

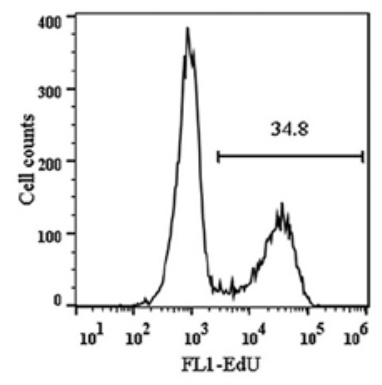

$\mathrm{HG}+$ Irbesartan

+ Pirfenidone

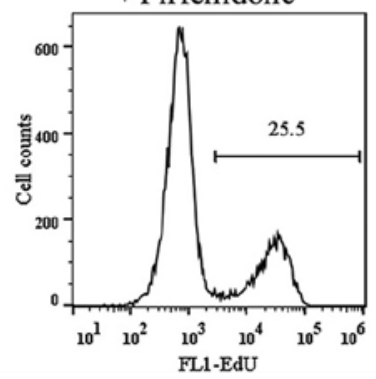

B

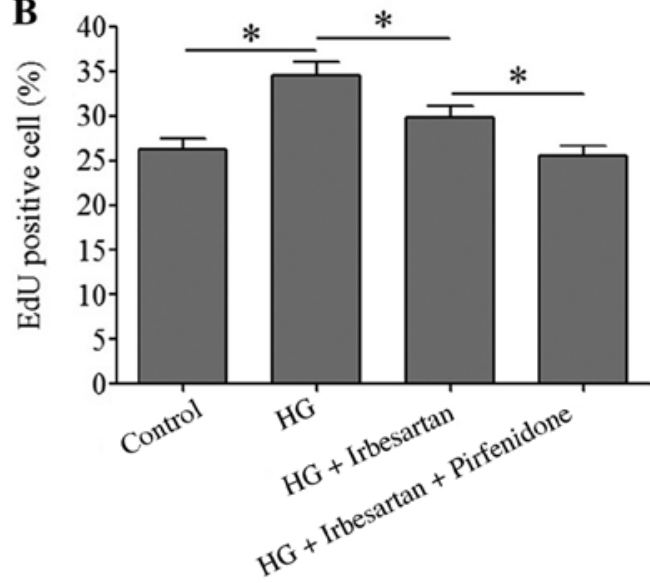

Figure 3. Irbesartan inhibits the proliferation of HG-treated RCF cells. (A) Flow cytometry detection of RCF cell proliferation. (B) Statistical comparison of the ratio of EdU-positive RCF cells. ${ }^{*} \mathrm{P}<0.05$. HG, high glucose.

Table V. PICP and PIIINP levels in RCF cell culture medium from each treatment group.

\begin{tabular}{lcrrr}
\hline Group & Control & HG & HG + Irbesartan & HG + Irbesartan + Pirfenidone \\
\hline PICP $(\mathrm{pg} / \mathrm{ml})$ & $615.8 \pm 31.9$ & $1186.6 \pm 43.8^{\mathrm{a}}$ & $926.5 \pm 36.9^{\mathrm{a}}$ & $811.8 \pm 35.1^{\mathrm{a}}$ \\
PIIINP $(\mathrm{pg} / \mathrm{ml})$ & $236.5 \pm 18.7$ & $458.4 \pm 37.5^{\mathrm{a}}$ & $364.3 \pm 26.5^{\mathrm{a}}$ & $306.7 \pm 24.7^{\mathrm{a}}$ \\
\hline
\end{tabular}

${ }^{a} \mathrm{P}<0.05$ vs. control group. HG, high glucose; PICP, procollagen carboxyl-terminal peptide; PIIINP, procollagen type III N-terminal peptide.

biological effects. In mammalian cells, three types of TGF $\beta 1$ receptors (T $\beta$ Rs) are expressed: T $\beta$ R-I, T $\beta$ R-II and T $\beta$ R-III (25). Moreover, T $\beta$ R-III lacks intrinsic activity and has no signal transduction function itself. The active forms of T $\beta$ R-II and T $\beta$ R-III respond to stimuli in the body and function in signal transduction (26). Smads have signal transduction functions and act in the cytoplasm with T $\beta$ R-I kinase, which plays a key role in the regulation of the TGF $\beta 1 / \mathrm{Smad}$ pathway; within this pathway, Smad 2 and Smad3 mediate TGF $\beta 1$ protein signal transduction $(27,28)$. Under the stimulation of various factors, TGF $\beta 1$ combines with T $\beta$ R-II and $\mathrm{T} \beta \mathrm{R}-\mathrm{II}$ binds to T $\beta \mathrm{R}-\mathrm{I}$ in response to phosphorylation $(25,26)$. Phosphorylation-activated T $\beta R$-I then combines with Smad2/3. Moreover, phosphorylation-activated Smad2/3 combines with Smad4 to form a protein polymer, which is transferred from the cytoplasm to the nucleus and regulates the transcription and expression of a variety of downstream target genes, including Col-I, Col-III and $\alpha$-SMA (29-31). In a positive feedback mechanism, the protein complex acts on the promoter region of the TGF $\beta 1$ gene to promote its expression and TGF $\beta 1$ autocrine signalling. In addition, TGF $\beta 1$ plays a positive feedback role by promoting the expression of the T $\beta$ R-I and T $\beta R$-II receptor genes and amplifying the TGF $\beta 1 / \mathrm{Smad} 2 / 3$ signalling pathway $(29,30)$.
TGF $\beta 1$ is the regulatory factor most closely related to MF (21). Increased expression and activation of TGF $\beta 1$ occurs within a common pathway and acts as an intermediate bridge for MF caused by several factors. Thus, TGF $\beta 1$ is considered to be a direct MF factor (32). Previous studies have revealed that Ang II signalling can lead to collagen deposition via a variety of pathways, including the 5'adenosine monophosphate-activated protein kinase-angiotensin converting enzyme 2 and CTGF-fractalkine pathways, leading to fibrosis $(33,34)$. Irbesartan, an Ang II receptor antagonist, affects the biological function of Ang II by blocking the binding of Ang II to its receptor (14). In a previous study examining ventricular fibrosis induced by hypertension, irbesartan regulated the degradation and synthesis of ECM by downregulating the expression of matrix metalloproteinase-2 and TIMP metallopeptidase inhibitor 2 to reduce the degree of ventricular MF (35). Irbesartan is widely used in the treatment of hypertension and type II diabetic nephropathy with hypertension and has been shown to alleviate MF caused by renal vascular hypertension (15). However, to the best of our knowledge, there have been few reports in China or elsewhere on whether irbesartan can reverse DM-induced MF. Therefore, the aim of the present study was to investigate whether irbesartan can improve MF in DM model rats. 
Lipid metabolism dysfunction is an important factor in type $2 \mathrm{DM}$ pathogenesis (36). Therefore, the present study examined the serum TC level in STZ-induced DM model to determine whether the model was successfully established. Compared with the control group, the DCM group had significantly higher blood glucose levels and abnormal blood lipid levels, indicating the successful establishment of the DM rat model. Furthermore, the HWI and LVWI of DCM rats were significantly increased. The myocardial content of type I collagen and hydroxyproline in DCM rats was significantly higher compared with control rats, suggesting that the myocardial tissue of DCM rats had obvious fibrotic changes. In line with other studies, such as that by Shen et al (37), significantly increased levels of the type I collagen COL1A1 have been shown in cardiac muscle tissue in DM rats compared with control rats.

In the present study, irbesartan-treated DCM rats exhibited significantly milder fibrosis and lower TGF $\beta 1$ and $\mathrm{p}-\mathrm{Smad} 2 / 3$ expression in the myocardium compared with DCM rats, suggesting that irbesartan may reduce $\mathrm{TGF} \beta 1 / \mathrm{Smad} 2 / 3$ pathway activation to alleviate MF in DM rats by reducing the expression of TGF $\beta 1$. Lv et al (38) investigated irbesartan and visceral fibrosis in diabetic nephropathy model animals, and found that irbesartan significantly reduced the expression of TGF $\beta 1$ in the glomerular tissue of diabetic nephropathy rats. Moreover, Tuncdemir et al (39) revealed that irbesartan treatment significantly reduced TGF $\beta 1$ expression in the glomeruli of diabetic nephropathy rats. Furthermore, irbesartan has been shown to significantly inhibit remodelling and fibrosis of the myocardium in hypertensive rats by downregulating the expression of TGF $\beta 1$ (40). In a study by Kataoka et al (41), irbesartan was revealed to serve a role in downregulating the expression of TGF $\beta 1$ and inhibiting MF in atrial tachycardia models. In addition, Tanaka et al (42) demonstrated that irbesartan significantly inhibited bleomycin-induced pulmonary fibrosis and reduced the expression of TGF $\beta 1$ in lung tissue. It has also been shown that the degree of renal tubulointerstitial fibrosis is significantly lower in irbesartan-treated animals compared with untreated animals, and that the expression of TGF $\beta 1$ and the phosphorylation of Smad2 are also significantly inhibited in irbesartan-treated animals (43). Using a rat model of hepatic fibrosis induced by bile duct ligation, Kim et al (44) reported that irbesartan significantly inhibited the expression of TGF $\beta 1$ in the liver and reduced the severity of liver fibrosis. Thus, these previous findings suggest that irbesartan can inhibit fibrosis of the viscera by regulating the expression of TGF $\beta 1$ and downregulating the activity of the TGF $\beta 1 / \mathrm{Smad} 2 / 3$ pathway, which is consistent with the present results.

Through further in vitro experiments, the present study also demonstrated that irbesartan decreased TGF $\beta 1$ expression in RCF cells, inhibiting Smad2/3 activity. Enhancement and overactivation of cardiac fibroblast proliferation play important roles in the development of MF (45). Cardiac fibroblast activation mainly manifests as increased amounts of ECM around cardiac fibroblasts (46). Moreover, ratio of type I collagen to type III collagen synthesis is an important metric for cardiac fibroblast activation (47). Therefore, detection of the amounts of the PICP before the formation of type I collagen and PIIINP before the formation of type III collagen has become a common method that reflects the content of type I and type III collagen proteins (48). The present study found that irbesartan significantly inhibited the proliferation of RCF cells under HG conditions and reduced the content of PICP and PIIINP. Combined treatment with pirfenidone further enhanced the inhibitory effect of irbesartan on RCF cell proliferation, collagen synthesis and fibroblast activation. As there is no RAAS in cultured cells in vitro, irbesartan may regulate the expression of TGF $\beta 1$ directly or indirectly via other mechanisms and affect the activity of the TGF $31 /$ Smad2/3 pathway, thus inhibiting cardiac myocyte fibrosis. Similarly, in vitro studies by Lv et al (38) have revealed that irbesartan significantly downregulated the expression of TGF $\beta 1$, collagen IV and fibronectin in HG-treated glomerular mesangial cells and inhibited fibrosis of HG-treated mesangial cells, indicating that irbesartan can inhibit fibrosis by directly downregulating TGF $\beta 1$ without relying on the RAAS system. Thus, it was indicated that lowering the expression of TGF $\beta 1$ and the activity of the TGF $\beta 1 / \mathrm{Smad} 2 / 3$ pathway may be one of the mechanisms via which irbesartan reduces MF in DM rats. However, irbesartan may also regulate MF in DM rats via other mechanisms; for instance, Liu et al (49) have shown that irbesartan alleviated MF in DM rats by regulating protein kinase $\mathrm{D}$ and the endoplasmic reticulum stress system. As this study was limited in its examination of other possible mechanisms, future studies will investigate the other possible mechanisms, including those of oxidative stressor immunomodulation, via which irbesartan affects diabetic MF.

In conclusion, the present results suggested that irbesartan may downregulate TGF $\beta 1$ expression, inhibit TGF $\beta 1 / \mathrm{Smad} 2 / 3$ pathway activity and promote collagen synthesis to reduce $\mathrm{MF}$ lesions and improve myocardial function.

\section{Acknowledgements}

Not applicable.

\section{Funding}

No funding was received.

\section{Availability of data and materials}

The datasets used and/or analyzed during the current study are available from the corresponding author on reasonable request.

\section{Authors' contributions}

MZ and HZ designed the experiments. QL, YL and JZ performed the experiments. YL and JZ collected and analyzed the data. MZ and HZ drafted the manuscript. All authors read and approved the final manuscript.

\section{Ethics approval and consent to participate}

The present study was approved by the Animal Ethics Committee and was conducted in accordance to the relevant agreements with the Beijing Chaoyang Hospital of the Capital Medical University (approval no. 201705231). All procedures were performed in accordance with the Guidance Suggestions 
for the Care and Use of Laboratory Animals, formulated by the Ministry of Science and Technology of China.

\section{Patient consent for publication}

Not applicable.

\section{Competing interests}

The authors declare that they have no competing interests.

\section{References}

1. Chen J, Wang J, Zhang X and Zhu H: Inverse relationship between serum bilirubin levels and diabetic foot in Chinese patients with type 2 diabetes mellitus. Med Sci Monit 23: 5916-5923, 2017.

2. Xu T, Weng Z, Pei C, Yu S, Chen Y, Guo W, Wang X, Luo P and Sun J: The relationship between neutrophil-to-lymphocyte ratio and diabetic peripheral neuropathy in type 2 diabetes mellitus. Medicine (Baltimore) 96: e8289, 2017.

3. Russo I, and Frangogiannis NG: Diabetes-associated cardiac fibrosis: Cellular effectors, molecular mechanisms and therapeutic opportunities. J Mol Cell Cardiol 90: 84-93, 2016.

4. Dillmann WH: Diabetic cardiomyopathy. Circu Res 124: 1160-1162, 2019

5. Zhang X, Pan L, Yang K, Fu Y, Liu Y, Chi J, Zhang X, Hong S, Ma X and Yin X: H3 relaxin protects against myocardial injury in experimental diabetic cardiomyopathy by inhibiting myocardial apoptosis, fibrosis and inflammation. Cell Physiol Biochem 43: 1311-1324, 2017.

6. Zou C, Liu X, Xie R, Bao Y, Jin Q, Jia X, Li L and Liu R: Deferiprone attenuates inflammation and myocardial fibrosis in diabetic cardiomyopathy rats. Biochem Biophys Res Commun 486: 930-936, 2017.

7. Wang L, Li J and Li D: Losartan reduces myocardial interstitial fibrosis in diabetic cardiomyopathy rats by inhibiting JAK/STAT signaling pathway. Int J Clin Exp Pathol 8: 466-473, 2015.

8. He-He H, Chen DQ, Wang YN, Feng YL, Cao G, Vaziri ND and Zhao YY: New insights into TGF- $\beta /$ smad signaling in tissue fibrosis. Chem Biol Interact 2018: 76-83, 2018.

9. Meng XM, Nikolic-Paterson DJ and Lan HY: TGF- $\beta$ : The master regulator of fibrosis. Nat Rev Nephrol 12: 325-338, 2016.

10. Xu F, Liu C, Zhou D and Zhang L: TGF- $\beta$ /SMAD pathway and its regulation in hepatic fibrosis. J Histochem Cytochem 64 157-167, 2016.

11. Estato V, Obadia N, Carvalho-Tavares J, Freitas FS, Reis P, Neto HC, Lessa MA and Tibiriçá E: Blockade of the reninangiotensin system improves cerebral microcirculatory perfusion in diabetic hypertensive rats. Microvasc Res 87: 41-49, 2013.

12. Wong TC, Piehler KM, Kang IA, Kadakkal A, Kellman P, Schwartzman DS, Mulukutla SR, Simon MA, Shroff SG, Kuller LH and Schelbert EB: Myocardial extracellular volume fraction quantified by cardiovascular magnetic resonance is increased in diabetes and associated with mortality and incident heart failure admission. Eur Heart J 35: 657-664, 2014.

13. Patel BM and Mehta AA: Aldosterone and angiotensin: Role in diabetes and cardiovascular diseases. Eur J Pharmacol 697: 1-12, 2012.

14. Parving HH, Lehnert H, Bröchner-Mortensen J, Gomis R, Andersen $\mathrm{S}$ and Arner P; Irbesartan in Patients with Type 2 Diabetes and Microalbuminuria Study Group: The effect of irbesartan on the development of diabetic nephropathy in patients with type 2 diabetes. N Engl J Med 345: 870-878, 2001.

15. Croom KF, Curran MP, Goa KL and Perry CM: Irbesartan: A review of its use in hypertension and in the management of diabetic nephropathy. Drugs 64: 999-1028, 2004.

16. Nako H, Kataoka K, Koibuchi N, Dong YF, Toyama K, Yamamoto E, Yasuda O, Ichijo $\mathrm{H}$, Ogawa $\mathrm{H}$ and Kim-Mitsuyama S: Novel mechanism of angiotensin II-induced cardiac injury in hypertensive rats: The critical role of ASK1 and VEGF. Hypertens Res 35: 194-200, 2012.

17. Castoldi G, Di Gioia CR, Bombardi C, Catalucci D, Corradi B Gualazzi MG, Leopizzi M, Mancini M, Zerbini G, Condorelli G and Stella A: MiR-133a regulates collagen 1A1: Potential role of miR-133a in myocardial fibrosis in angiotensin II-dependent hypertension. J Cell Physiol 227: 850-856, 2012.
18. Whaley-Connell A, Habibi J, Cooper SA, Demarco VG, Hayden MR, Stump CS, Link D, Ferrario CM and Sowers JR: Effect of renin inhibition and AT1R blockade on myocardial remodeling in the transgenic ren2 rat. Am J Physiol Endocrinol Metab 295: E103-E109, 2008.

19. National Research Council (US) Committee for the Update of the Guide for the Care and Use of Laboratory Animals: Guide for the Care and Use of Laboratory Animals. 8th edition. National Academies Press, Washington, DC, 2011. Available from: https:// www.ncbi.nlm.nih.gov/books/NBK54050/ doi: 10.17226/12910.

20. Dai H, Zheng M, Tang Rn, Ma Kl, Ni J and Liu BC: Inhibition of integrin-linked kinase by angiotensin II receptor antagonist, irbesartan attenuates podocyte injury in diabetic rats. Chin Med J (Engl) 125: 888-893, 2012.

21. Guo Y, Gupte M, Umbarkar P, Singh AP, Sui JY, Force T and Lal H: Entanglement of GSK-3 $\beta, \beta$-catenin and TGF- $\beta 1$ signaling network to regulate myocardial fibrosis. J Mol Cell Cardiol 110: 109-120, 2017.

22. Yang D, Li L, Qian S and Liu L: Evodiamine ameliorates liver fibrosis in rats via TGF-beta1/smad signaling pathway. J Natl Med 72: 145-154, 2017.

23. Yang T, Wang J, Pang Y, Dang X, Ren H, Liu Y, Chen M and Shang D: Emodin suppresses silica-induced lung fibrosis by promoting sirt1 signaling via direct contact. Mol Med Rep 14: 4643-4649, 2016.

24. Li H, Cai H, Deng J, Tu X, Sun Y, Huang Z, Ding Z, Dong L, Chen J, Zang Y and Zhang J: TGF-beta-mediated upregulation of sox9 in fibroblast promotes renal fibrosis. Biochim Biophys Acta Mol Basis Dis 1864: 520-532, 2018.

25. Kajdaniuk D, Marek B, Borgiel-Marek H and Kos-Kudła B: Transforming growth factor $\beta 1$ (TGF $\beta 1$ ) in physiology and pathology. Endokrynol Pol 64: 384-396, 2013.

26. Chen G, Grotendorst G, Eichholtz T and Khalil N: GM-CSF increases airway smooth muscle cell connective tissue expression by inducing TGF- $\beta$ receptors. Am J Physiol Lung Cell Mol Physiol 284: L548-L556, 2003.

27. Loboda A, Sobczak M, Jozkowicz A and Dulak J: TGF-beta1/smads and miR-21 in renal fibrosis and inflammation. Med Inflamm 2016: 8319283, 2016.

28. Li Y, Yang Y, Yu D and Liang Q: The effect of tanshinone IIA upon the TGF-beta1/smads signaling pathway in hypertrophic myocardium of hypertensive rats. J HuazhongUnivSciTechnolog Med Sci 29: 476-480, 2009.

29. Yuan X, Gong Z, Wang B, Guo X, Yang L, Li D and Zhang Y: Astragaloside inhibits hepatic fibrosis by modulation of TGF-beta1/smad signaling pathway. evidence-based complementary and alternative medicine. Evid Based Complement Alternat Med 2018: 3231647, 2018.

30. Wang S, Zhao X, Yan S, Chen B and Shi J: Knockdown of NLRC5 inhibits renal fibroblast activation via modulating TGF-beta1/smad signaling pathway. Eur J Pharmacol 829: 38-43, 2018.

31. Yu B, Li W, Al F and Chen Z: MicroRNA-33a deficiency inhibits proliferation and fibrosis through inactivation of TGF-beta/smad pathway in human cardiac fibroblasts. Pharmazie 72: 456-460, 2017.

32. Zhang Y, Shao L, Ma A, Guan G, Wang J, Wang Y and Tian G: Telmisartan delays myocardial fibrosis in rats with hypertensive left ventricular hypertrophy by TGF-beta1/smad signal pathway. Hypertens Res 37: 43-49, 2014.

33. Zhang ZZ, Cheng YW, Jin HY, Chang Q, Shang QH, Xu YL, Chen LX, Xu R, Song B and Zhong JC: The sirtuin 6 prevents angiotensin II-mediated myocardial fibrosis and injury by targeting AMPK-ACE2 signaling. Oncotarget 8: 72302-72314, 2017.

34. Roth L, Schrijvers DM, Martinet W and De Meyer GR: Angiotensin II increases coronary fibrosis, cardiac hypertrophy and the incidence of myocardial infarctions in $\mathrm{ApoE}^{-/ /} \mathrm{Fbn} 1^{\mathrm{Cl039} \mathrm{G}+1-}$ mice. Acta Cardiol 71: 483-488, 2016.

35. Chen Q, Pang L, Huang S, Lei W and Huang D: Effects of emodin and irbesartan on ventricular fibrosis in goldblatt hypertensive rats. Pharmazie 69: 374-378, 2014.

36. Ritchie RH, Zerenturk EJ, Prakoso D and Calkin AC: Lipid metabolism and its implications for type 1 diabetes-associated cardiomyopathy. J Mol Endocrinol 58: R225-R240, 2017.

37. Shen N, Li X, Zhou T, Bilal MU, Du N, Hu Y, Qin W, Xie Y, Wang H, Wu J, et al: Shensong Yangxin capsule prevents diabetic myocardial fibrosis by inhibiting TGF-beta1/smad signaling. J Ethnopharmacol 157: 161-170, 2014. 
38. Lv J, Wang Z, Wang Y, Sun W, Zhou J, Wang M, Liu WJ and Wang Y: Renoprotective effect of the shen-yan-fang-shuai formula by inhibiting TNF-alpha/NF-kappaB signaling pathway in diabetic rats. J Diabetes Res 2017: 4319057, 2017.

39. Tunçdemir M and Oztürk M: The effects of angiotensin-II receptor blockers on podocyte damage and glomerular apoptosis in a rat model of experimental streptozotocin-induced diabetic nephropathy. Acta Histochem 113: 826-832, 2011.

40. Chen C, Liang Z, Chen Q and Li ZG: Irbesartan and emodin on myocardial remodeling in Goldblatt hypertensive rats. J Cardiovasc Pharm 60: 375-380, 2012.

41. Kataoka N, Nishida K, Kinoshita K, Sakamoto T, Nakatani Y, Tsujino Y, Mizumaki K, Inoue H and Kinugawa K: Effect of irbesartan on development of atrial fibrosis and atrial fibrillation in a canine atrial tachycardia model with left ventricular dysfunction, association with p53. Heart Vessels 31: 2053-2060, 2016.

42. Tanaka J, Tajima S, Asakawa K, Sakagami T, Moriyama H, Takada T, Suzuki E and Narita I: Preventive effect of irbesartan on bleomycin-induced lung injury in mice. Respir Investig 51: 76-83, 2013.

43. Zhao G, Zhao H, Tu L, Xu X, Zheng C, Jiang M, Wang P and Wang D: Effects and mechanism of irbesartan on tubulointerstitial fibrosis in 5/6 nephrectomized rats. J Huazhong Univ Sci Technol Med Sci 30: 48-54, 2010.

44. Kim MY, Baik SK, Park DH, Jang YO, Suk KT, Yea CJ, Lee IY, Kim JW, Kim HS, Kwon SO, et al: Angiotensin receptor blockers are superior to angiotensin-converting enzyme inhibitors in the suppression of hepatic fibrosis in a bile duct-ligated rat model. J Gastroenterol 43: 889-896, 2008.
45. Pellman J, Zhang J and Sheikh F: Myocyte-Fibroblast communication in cardiac fibrosis and arrhythmias: Mechanisms and model systems. J Mol Cell Cardiol 94: 22-31, 2016.

46. Ivey MJ and Tallquist MD: Defining the cardiac fibroblast. Circ J 80: 2269-2276, 2016

47. Jin-Cheng L, Zhou L, Wang F, Cheng ZQ and Rong C: Osthole decreases collagen I/III contents and their ratio in TGF- $\beta 1$-overexpressed mouse cardiac fibroblasts through regulating the TGF- $\beta$ /smad signaling pathway. Chin J Nat Med 16: 321-329, 2018.

48. Eriksen HA, Satta J, Risteli J, Veijola M, Väre P and Soini Y: Type I and type III collagen synthesis and composition in the valve matrix in aortic valve stenosis. Atherosclerosis 189: 91-98, 2006.

49. Liu X, Xu Q, Wang X, Zhao Z, Zhang L, Zhong L, Li L, Kang W, Zhang Y and Ge Z: Irbesartan ameliorates diabetic cardiomyopathy by regulating protein kinase D and ER stress activation in a type 2 diabetes rat model. Pharmacol Res 93: 43-51, 2015.

This work is licensed under a Creative Commons Attribution-NonCommercial-NoDerivatives 4.0 International (CC BY-NC-ND 4.0) License. 